\title{
The Use of Panoramic Interactive Videography as a Teaching Instrument in High School and University Biology Courses and in Environmental Public Education
}

\author{
Betty Black and Harold Heatwole \\ Department of Biology, North Carolina State University, Raleigh, \\ North Carolina 27695-7617, USA
}

\author{
betty black@ncsu.edu harold heatwole@ncsu.edu
}

\begin{abstract}
We created several interactive learning objects that illustrate organisms within their natural habitats by linking videos to "hotspots" within panoramic vistas of the habitat; students can access these at will and in whatever order they choose. By linking other vistas to hotspots within the primary panorama, the student can take a virtual field trip, examining different views of that habitat, and bringing up moving images of wildlife inhabiting the area. These customizable interactive teaching instruments are provided free of charge to educators who can modify them in whatever way they wish to suit their individual needs and to adapt them to the level of their students. They were designed in accordance with the needs expressed by teachers and were found to be effective as teaching instruments.
\end{abstract}

Keywords: customization, habitats, interactivity, learning objects, panoramic vistas, teaching instruments, videography, wildlife

\section{Introduction}

Contemporary students learn in different ways than did previous generations as attitudes, perceptions, and experiences in the modern world are quite different than they were only a few years ago (Brown, 1997; Brumfield, 2005; Dede, 1997; Oblinger \& Oblinger, 2005) and the rate of change seems to be accelerating. Part of the revolution in learning has been stimulated by technological advances that provide a wealth of visual material not previously available. Even young students are now competent in operating computers and in using sophisticated software, and this has opened the door to providing them with opportunities for interacting with graphic learning objects in creative ways (Brown, 2005). Often high school students are now more adept at manipulating electronic media than are their teachers. The purpose of the present project was to de-

Material published as part of this publication, either on-line or in print, is copyrighted by the Informing Science Institute. Permission to make digital or paper copy of part or all of these works for personal or classroom use is granted without fee provided that the copies are not made or distributed for profit or commercial advantage AND that copies 1) bear this notice in full and 2) give the full citation on the first page. It is permissible to abstract these works so long as credit is given. To copy in all other cases or to republish or to post on a server or to redistribute to lists requires specific permission and payment of a fee. Contact Publisher@InformingScience.org to request redistribution permission. velop teaching methods and materials that would enable such teachers to keep abreast of a fast-moving technology and of the needs of an ever more demanding student body. There were eight criteria used in selecting the type of learning objects to be developed. We felt they must be:

(1) Visually Based: Black et al. (2007) reported on students' assessments 
of teaching aids in various courses in biology over a period of five years. Visual aids ranked the highest (mean 4.6-4.8 out of 5.0) whereas text books ranked the lowest (2.6-3.6). The preference for visual aids increased year by year. Among the various types of visual aids, videos were the top preference followed in descending order by animations and static images. The probable reason why videography has a greater impact than still photography is that it provides a dynamic approach in tune with modern students' modes of learning.

(2) Diverse: In disciplines such as behavior and ecology in which portrayal both of the habitat on a descriptive, large scale and of the movement of individual organisms within it are important for understanding ecological interactions, a combination of static and mobile images is maximally effective. This is particularly true when features are integrated that allow a student to shift between the two modes in an interactive way.

(3) Interactive: Students are more highly motivated, maintain concentration longer, and learn better if they have an active role in the teaching/learning process. Student evaluations of previous interactive learning objects produced for an Introductory Biology website revealed that the interactive features and animations were the website's most popular feature, with 75$92 \%$ of students agreeing with the statement that this approach helped them build an understanding of concepts (Black et al. 2007).

(4) Suitable: At the beginning of this project we interviewed a number of high school teachers attending a meeting of the American Institute of Biological Sciences. There was unanimity of agreement that what they needed were short video clips or multimedia learning objects designed to illustrate particular points, not long documentaries, excellent though they are. Accordingly, we produced a series of short video clips and interactive learning objects on a variety of biological topics and prepared a $\mathrm{CD}$ of them that we sent to 500 educators, primarily high school teachers and college instructors, for their comment. The recipients reported their preferences from the array of material we provided and we used that as a guide for producing clips to be incorporated as hotspots in our panoramic vistas.

(5) Flexible: Many topics in biology are of interest to students of greatly different ages from kindergarten to graduate school. We set out to develop an instrument that could scale the same material to different levels with a minimum of effort. For example, the same video could have quite different audio associated with it depending on its target audience. The kind and degree in interactivity would vary with the background of the participant; a more difficult and challenging task would be set for an advanced audience compared to one in an introductory course.

(6) Customizable by the client: No learning object will meet the needs of all potential clients. For example, some of the respondents to our sample of video clips were teachers whose instruction was given in a language other than English. The ability to remove the audio and record a substitute one in a different language was suggested as a desirable feature. Also, if a client were able to change the difficulty level of the audio narration, it could be adapted for different audiences (see criterion 5).

(7) Composed of readily available, commercial ingredients: If clients are to be able to customize the product (see criterion 6), it should consist of common, commercially available ingredients that are user-friendly.

(8) Of low cost to clients: Most teachers have limited budgets and therefore for a teaching instrument to be widely used, it needs to be made available either gratis or at a reasonable cost. The teachers we interviewed (see criterion 4) all reported that they could not afford all the videos they would like. There is a need to reduce the cost of high-quality materials.

This presentation describes how we met these criteria in producing a learning object that is innovative, versatile and readily available to educators at a variety of levels and for minimal cost. 


\section{Methods}

The learning object described in this presentation was designed to promote understanding of plants and animals within their natural habitat. We created a $360^{\circ}$ panorama of a natural area (a deciduous, temperate forest), then utilized "hotspots" within the panorama to link video clips of organisms living in different parts of the habitat. To assure authenticity of the forest environment, we visited a local forest area and produced the panorama and most of the video, using organisms that we found there. When organisms were too small to be easily seen, we collected samples and videographed them in our microscopy laboratory at the University.

This approach required the purchase of photographic equipment and software (Table 1).

Table 1. Tools used in creating the forest panorama

\begin{tabular}{|l|l|l|}
\hline $\begin{array}{l}\text { Application or } \\
\text { Equipment }\end{array}$ & $\begin{array}{l}\text { Operating } \\
\text { system }\end{array}$ & Comments \\
\hline $\begin{array}{l}\text { QuickTime } \\
\text { Pro }\end{array}$ & $\begin{array}{c}\text { Mac OS, } \\
\text { Windows }\end{array}$ & $\begin{array}{l}\text { Simple editing and conversion tools for Quick- } \\
\text { time }^{\mathrm{TM}} \text { movies }\end{array}$ \\
\hline $\begin{array}{c}\text { VR } \\
\text { ToolWorx }\end{array}$ & $\begin{array}{c}\text { Mac OS, } \\
\text { Windows }\end{array}$ & $\begin{array}{l}\text { VR multinode creation tool for panoramic movies; } \\
\text { we have recently switched to Pano2VR } \\
\text { export panoramic movies with hotspots in html5 } \\
\text { format. }\end{array}$ \\
\hline $\begin{array}{l}\text { 0-360 } \\
\text { Unwrapper }\end{array}$ & $\begin{array}{c}\text { Mac OS, } \\
\text { Windows } \\
\text { movies }\end{array}$ \\
\hline $\begin{array}{l}\text { Cannon Power- } \\
\text { shot G5 Digital } \\
\text { Camera }\end{array}$ & NA & $\begin{array}{l}\text { High-quality, 5 mega-pixel camera for taking } \\
\text { panoramic pictures }\end{array}$ \\
\hline $\begin{array}{c}\text { Cannon XL- } \\
\text { camcorder }\end{array}$ & NA & $\begin{array}{l}\text { High-quality camcorder with zoom lens for video- } \\
\text { graphing }\end{array}$ \\
\hline
\end{tabular}

To create the forest panorama, we used a parabolic mirror mounted on a digital camera. This allowed a $360^{\circ}$ image to be captured with a single camera shot. Free VR software could then be used to "unwrap" the image and import it into software designed to create panoramic QuickTime $\mathrm{VR}^{\mathrm{TM}}$ movies. While in the forest, we also videographed close-up regions of nine areas within view of the panoramic image. Samples from some areas, such as water from a tree hole and leaf litter, were collected and videographed in the laboratory using a stereomicroscope equipped with a digital camcorder. In our initial trip to the forest, we were accompanied by Hal Meeks, a multimedia consultant in the College of Agriculture and Life Sciences, who assisted in use of the equipment. When we returned to campus, we downloaded the video into a Macintosh computer and exported it as Quicktime ${ }^{\mathrm{TM}}$ movies. Several undergraduate Biology majors assisted in videomicroscopy, downloading, and editing of video. We added audio narration to the video clips of areas within the panorama and embedded all video clips on HTML pages. In the final step of creating an interactive learning object, we linked these pages to hotspots in the panoramic image and linked additional video clips of animals to the pages. The final product was exported as a Quick- 
Time VR ${ }^{\mathrm{TM}}$ movie. We have recently acquired software that can export the panoramic movie as HTML5 (Pano2VR 3.0 TM, Garden Gnome Software) and plan to use this format in the future.

\section{Results}

\section{Operation of the Learning Object}

The panoramic vista is opened from a web page (using the QuickTime ${ }^{\mathrm{TM}}$ player). The user can then rotate around the horizon using the mouse to move the cursor to the left or right, depending one the direction of movement desired, or by using arrow keys on the keyboard. The entire horizon can be scanned over $360^{\circ}$ and multiple circuits can be achieved in a seamless fashion. Any hotspot can be selected by clicking on it when the cursor changes shape, and a video emerges that illustrates that region of the environment. The video is accompanied by audio narration that identifies the animals portrayed and informs about their habits, ecology and their role in the ecosystem featured in the panorama. The user can revisit hotspots at any time. If the user cannot easily identify hotspots, they can be outlined by clicking the "show hotspot" tool on the play bar (Figures 1 and 2).

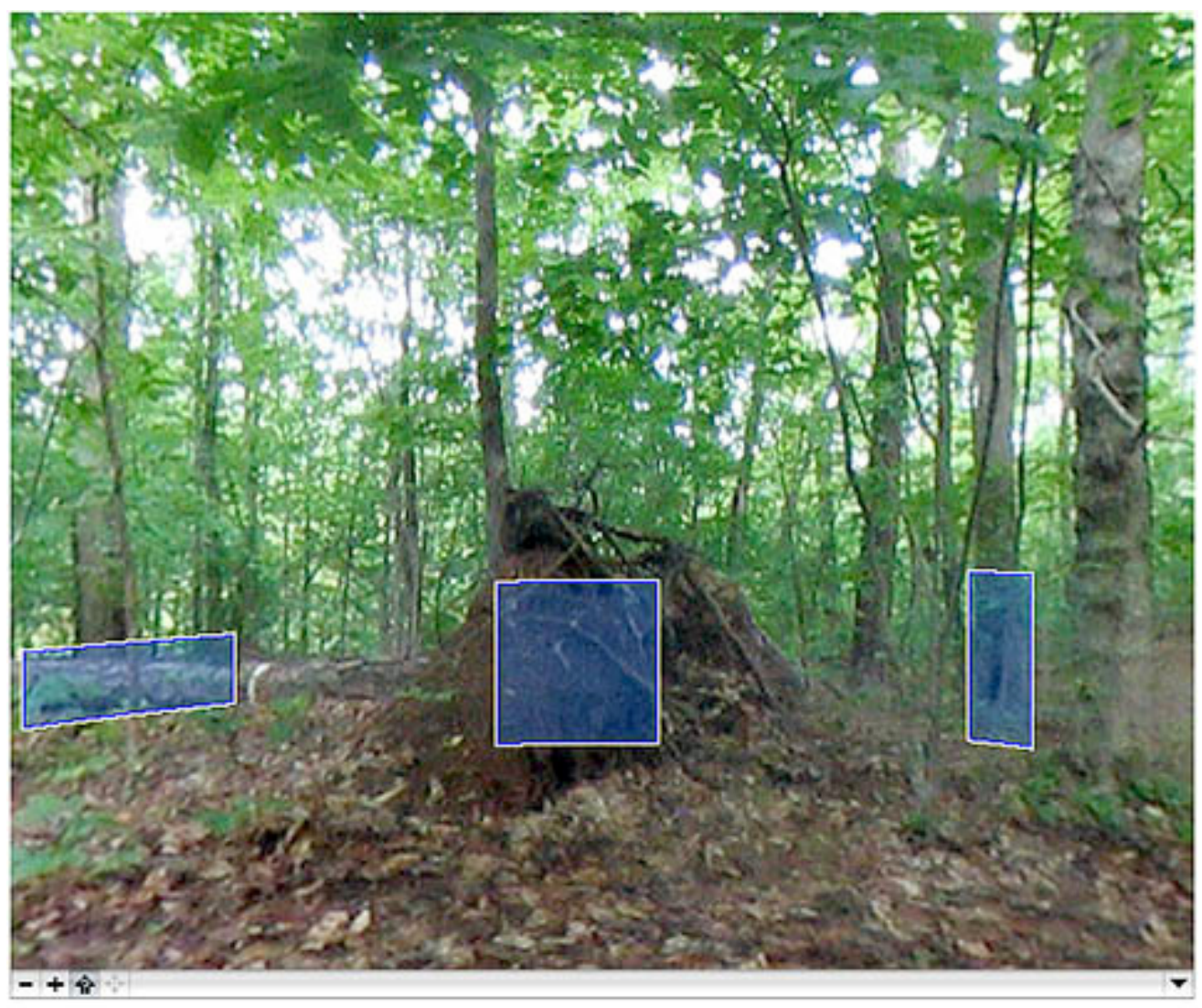

Figure 1. One view of the forest as displayed in a panoramic movie. The "show hotspots" tool has been selected and three hotspots are outlined by shaded squares. 


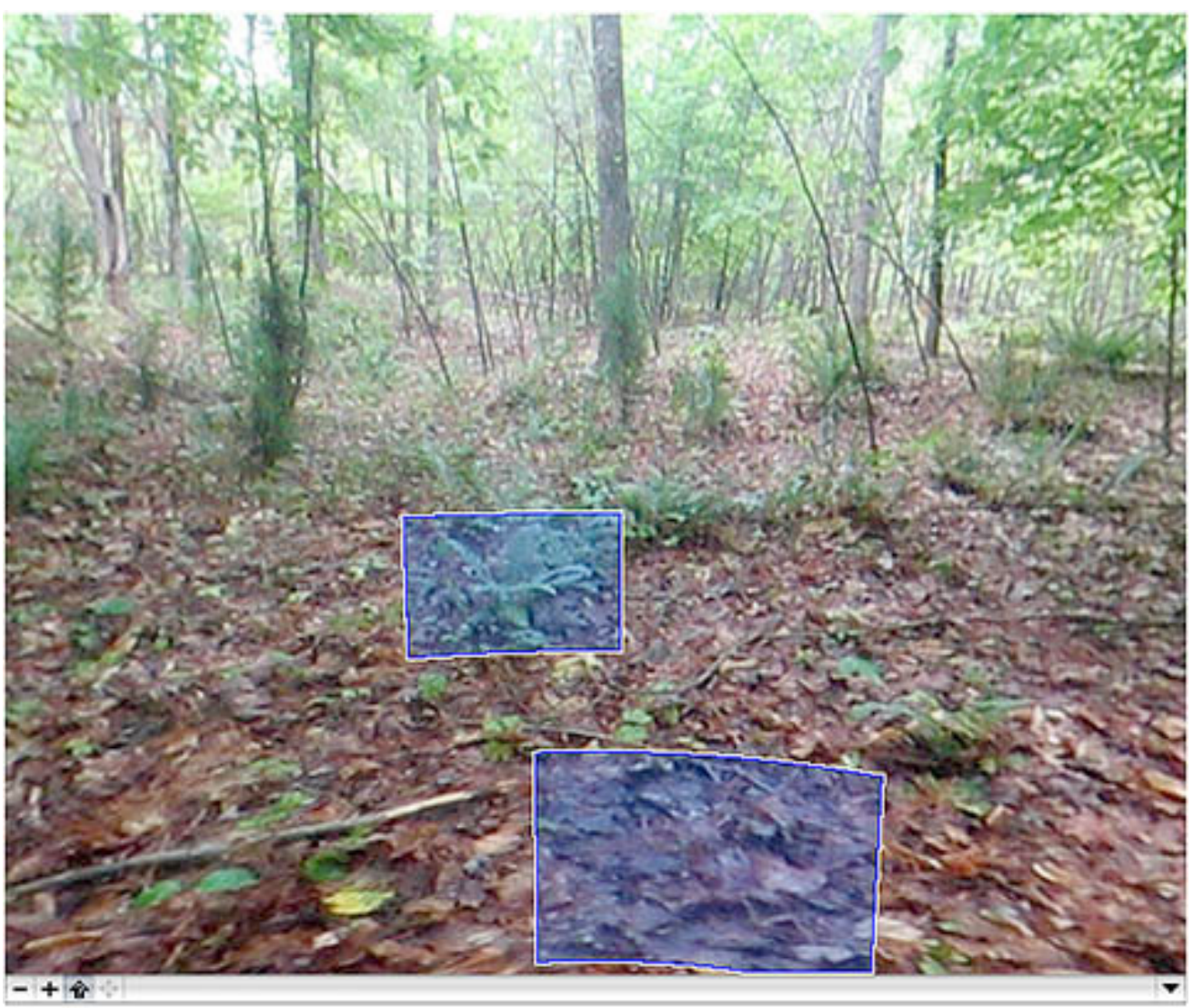

Figure 2. Another view of the forest after rotating the panorama. The "show hotspots" tool has been selected and two hotspots are outlined by shaded squares.

Most of the hotspot-regions contain small animals that are best viewed under a microscope. Thus, most region pages contain names of animals beneath the video. Clicking on a name pops up a new page containing a video clip of that animal (Figures 3 and 4). Consequently, the panoramic learning object is visually based and highly interactive. 


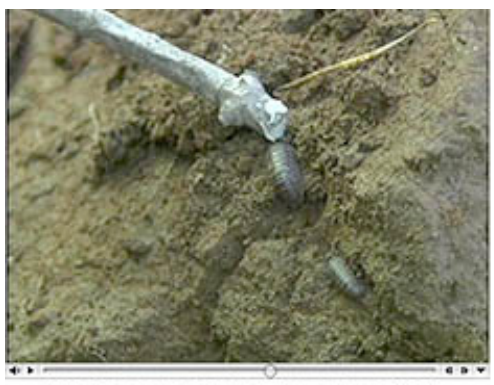

Select a name below to view more animals that live in loose dirt.

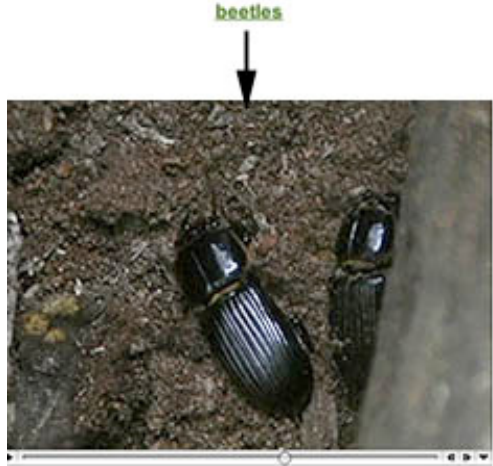

Beetles digging in the loose soil

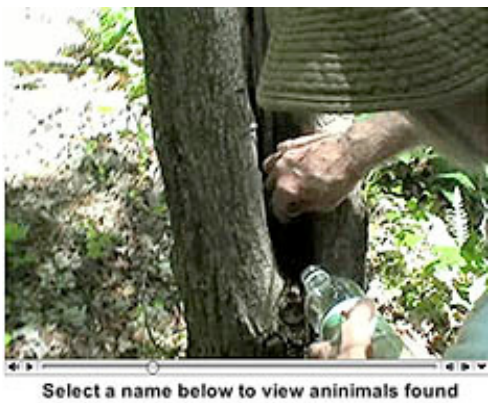

in the tree hole water.

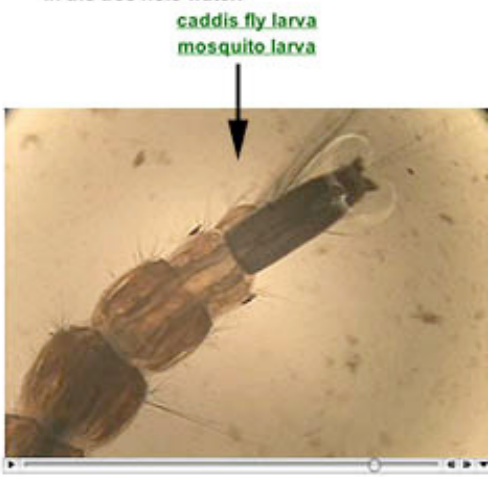

Mosquito larva from the tree hole water

Figure 3. Video clips linked to the forest panorama.

The first video is a close-up of the region indicated by the center hotspot in Figure 1. Clicking on the name "beetles" pops up a new window showing beetles digging in the soil around the roots of a fallen tree. The second video is a close-up of the hotspot on the right side of Figure 1. It shows Dr. Heatwole collecting a sample of water from within a tree hole. Clicking on the name "mosquito larva" pops up a new window showing the living larva as viewed under a stereomicroscope.
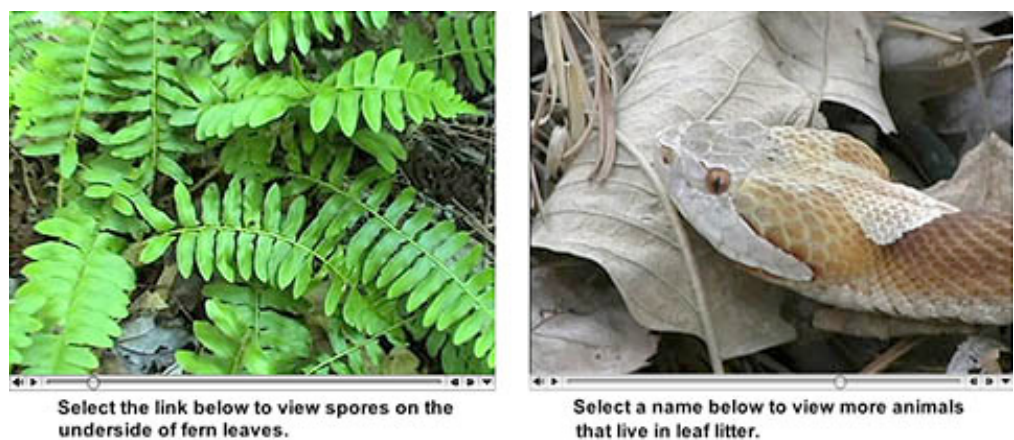

Select a name below to view more animals that live in leaf litter.
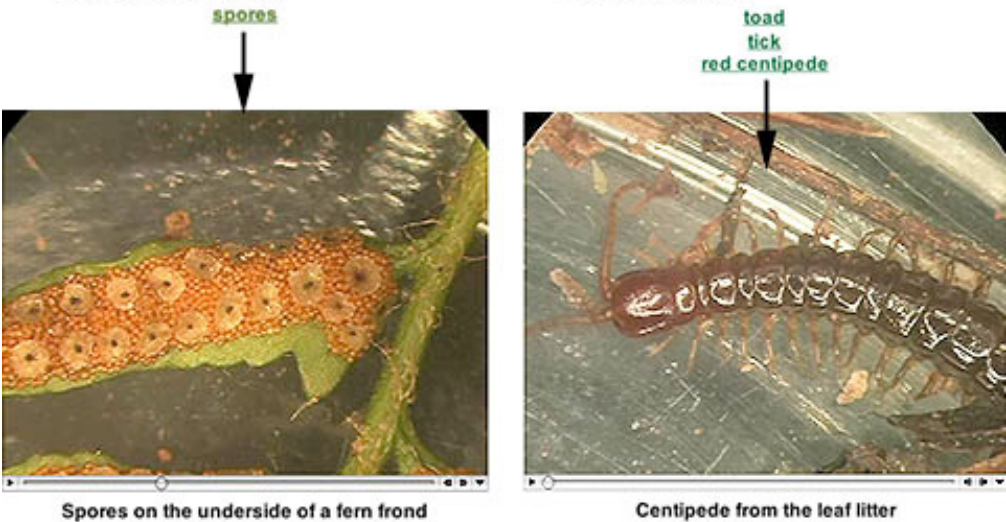

Spores on the underside of a fern frond

Centipede from the leaf litter 
Figure 4. Video clips linked to a second view of the forest panorama.

The first video is a close-up of the region indicated by the upper hotspot in Figure 2. As the user views the fern, a small insect can be seen crawling over a leaf. Clicking on the name "spores" pops up a new window showing spores on the underside of a fern leaf. The second video is a close-up of the hotspot on the bottom of Figure 2. It shows a copperhead snake crawling through the leaf litter. As the camera zooms in, details of the head come into view. Clicking on the name "red centipede" pops up a new window showing the living centipede as viewed under a stereomicroscope.

\section{Use of the Learning Object in Introductory Classes}

We are currently using the forest panorama in the distance education course "Introductory Biology I". The panoramic learning object comprises half of the online ecosystems laboratory in the course. Offering laboratories by distance education is especially challenging, since hands-on exercises are not possible. However, the online format does allow students to explore environments that would not be feasible in a classroom laboratory due to time and financial constraints. Hence, we have used forest panorama to simulate a field trip to a deciduous forest where students can explore the environment, discover some of the plants and animals that live there, and even "collect" samples for microscopic observation. The ecosystems assignment begins by introducing students to the forest environment. They view a map showing the global distribution of temperate, deciduous forests and a graph of rainfall per year required for various forest types. The introduction to the laboratory work ends with a description of forest stratification in which students learn about forest levels and representative organisms that live at each level. Students then enter the forest panorama and explore the various levels to discover a variety of plants and animals. As an organism is discovered, students are asked to place it in the appropriate forest stratum using a table downloaded from the course website. After completing the table, students submit it to WebAssign $^{\mathrm{TM}}$ (on online homework submission and quizzing site) as an image file (Figure 5).

Table of Plants and Animals in Schenck Forest

\begin{tabular}{|l|l|}
\hline \multicolumn{1}{|c|}{ Forest layer (stratum) } & \multicolumn{1}{|c|}{ Organisms found } \\
\hline Canopy & Deciduous trees, woodpecker, owl \\
\hline $\begin{array}{l}\text { Sapling layer } \\
\text { (includes tree hole) }\end{array}$ & Snail, mosquito larva, caddis fly larva, butterfly \\
\hline Shrub layer & Deer \\
\hline Herb layer & Small unidentified insects, spores, ferns, raccoon, fox \\
\hline $\begin{array}{l}\text { Ground layer } \\
\text { (includes logs \& leaf litter) }\end{array}$ & $\begin{array}{l}\text { Lizard, millipede, moss, rotifer, tardigrade, small } \\
\text { unidentified insect, tiny spiders, salamander, white } \\
\text { termites, ants with larvae, white centipede, flies, } \\
\text { copperhead snake, beetle, toad, tick, red centipede, }\end{array}$ \\
\hline $\begin{array}{l}\text { Subterranean layer } \\
\text { (soil) }\end{array}$ & Isopods, beetles, \\
\hline
\end{tabular}

Figure 5. Table of forest strata filled out by a student and submitted as an image for grading. Students in the ecosystems laboratory discover at least 30 plants and animals within the forest panorama. They list them in the appropriate forest stratum to indicate their understanding of the forest ecosystem. 
After they have completed the table, students use the same organisms to construct a productivity pyramid. They have learned about these pyramids in the "lecture" portion of the course and are now asked to show their understanding of trophic levels by filling out the image of a pyramid downloaded from the course website (Figure 6).

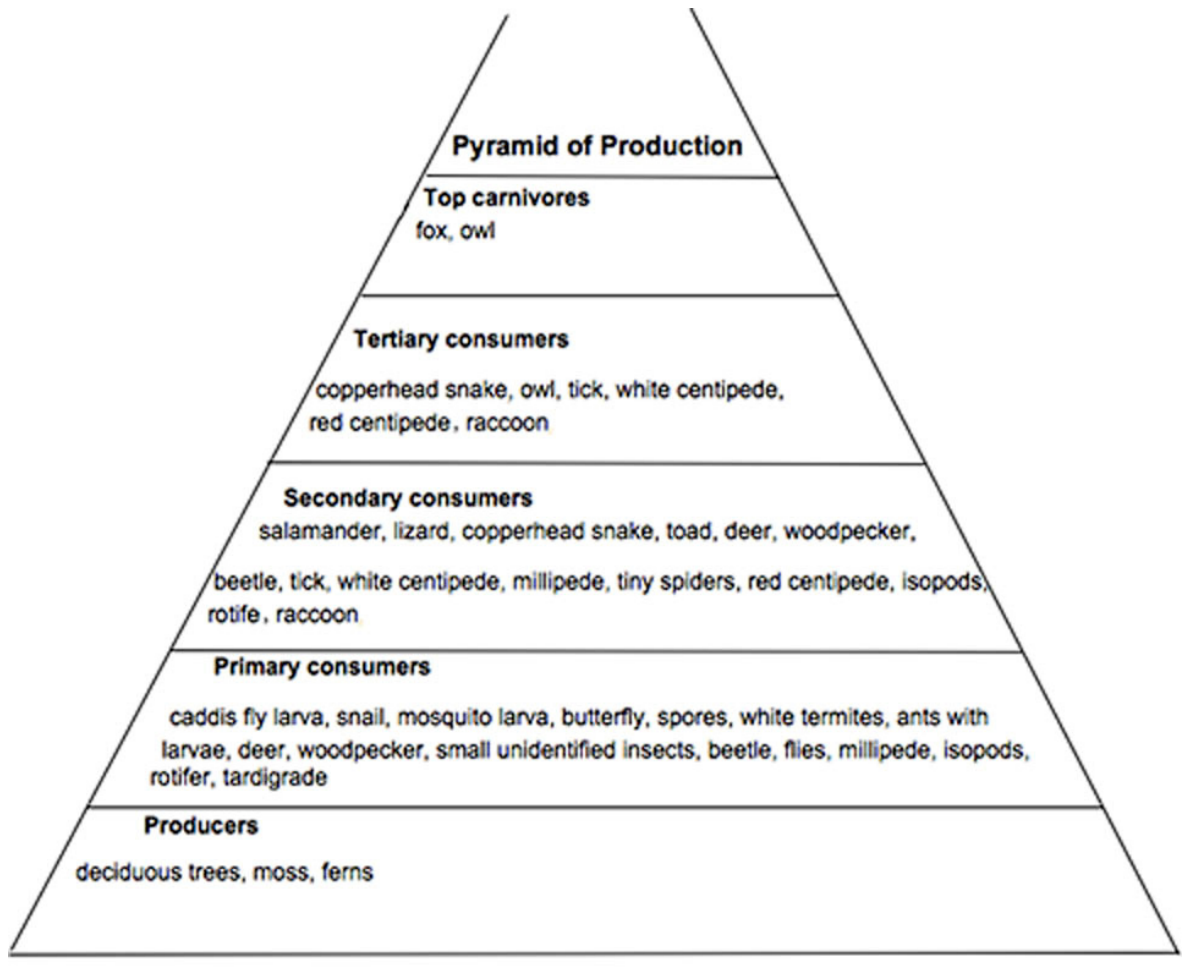

Figure 6. Productivity pyramid filled out by a student and submitted as an image for grading. Students must determine which of the organisms discovered in the forest panorama are producers or several different levels of consumers. This exercise fosters an understanding of the energy structure within an ecosystem.

Our online course features a homework submission system, WebAssign ${ }^{\mathrm{TM}}$, which allows submitted images to be graded quickly and efficiently. The instructor (in this case an undergraduate teaching assistant) can designate the question to be graded. All students' answers to that question then appear in a scrolling column. Clicking on the link in the student's answer box pops up the image that is viewed from its storage site, not downloaded to the grader's computer. The grader enters a score along with appropriate feedback for the student (Figure 7). Scores are automatically recorded in the online grade book. Scores and feedback may be viewed by the students at any time after the submission deadline. 


\section{Grade Essays and Files}

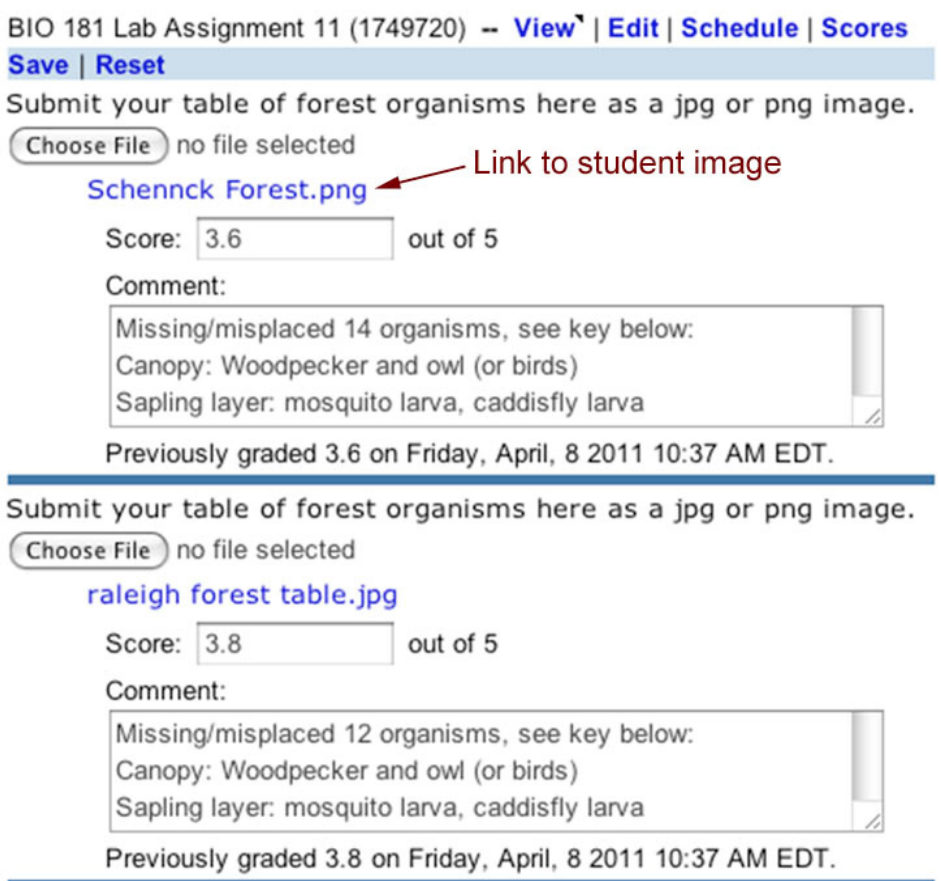

Figure 7. Image of WebAssign ${ }^{\mathrm{TM}}$ grading feature.

Two students' answers to the question about forest strata are shown. The link in the answer box brings up the completed table that is the answer to this question. Students' scores (out of five points for the question) are shown along with the grader's comments. Also note the "choose file" button that students utilize to upload their image files to WebAssign"M.

The ecosystems assignment contained five questions related to the forest panorama. This comprised 13 points (approximately half of the total assignment). The students did well on understanding concepts that are difficult for students taking their first biology course; the average score on the questions about the forest panorama was $80.7 \%$ (Figure 8). Furthermore, students were actively involved in discovering the organisms within the forest as opposed to being given a list of plants and animals with which to work. This enabled them to actually see where the organisms lived within a real ecosystem and promoted a highly visual form of learning. As an added benefit, students learned some details about individual species similar to the experience gained by accompanying instructors leading a physical field trip to the forest.

\begin{tabular}{rrrrrrr} 
Question \# & \multicolumn{2}{c}{$\mathbf{1}$} & $\mathbf{2}$ & $\mathbf{3}$ & $\mathbf{4}$ & \multicolumn{1}{c}{$\mathbf{5}$} \\
QID & Total & $\mathbf{1 7 3 0 0 3 5}$ & $\mathbf{1 7 3 0 0 3 6}$ & $\mathbf{1 7 3 0 0 3 7}$ & $\mathbf{1 7 3 0 0 5 1}$ & $\mathbf{1 7 3 0 0 5 2}$ \\
Points & $\mathbf{2 8}$ & 1 & 1 & 1 & 5 & 5 \\
scores analyzed & $\mathbf{1 3 6}$ & 136 & 136 & 136 & 136 & 136 \\
mean & $\mathbf{2 3 . 5}$ & 0.882 & 0.941 & 0.993 & 3.68 & 4.00 \\
median & $\mathbf{2 5 . 3}$ & 1.00 & 1.00 & 1.00 & 4.25 & 4.30 \\
\hline standard deviation & $\mathbf{5 . 4 2}$ & 0.322 & 0.235 & 0.0854 & 1.39 & 1.25 \\
min/max & $\mathbf{3 / 2 8}$ & $0 / 1$ & $0 / 1$ & $0 / 1$ & $0 / 5$ & $0 / 5$
\end{tabular}

Figure 8. WebAssign ${ }^{\mathrm{TM}}$ scores for the ecosystems laboratory assignment Questions 1-3 are multiple-choice questions worth one point each. Questions 4 and 5 are the forest strata table and productivity pyramid, respectively, worth five points each. The remaining points (out of a total of 28) are from the remainder of the assignment, unrelated to the panorama. 


\section{Discussion}

The eight criteria mentioned in the Introduction have been fulfilled by the forest panorama learning object. It is highly visual and uses a diversity of media, including a static panoramic image, colorful, dynamic video, and audio narration. The panorama is interactive in that users can choose hotspots in whatever order they wish to view the linked video and can revisit them as often as they wish. Additional interactivity is provided by a second layer of video clips, which are linked to the initial video pages. The panoramic learning object contains material suitable for a wide range of audiences and topics. We chose to use it as part of an ecosystems assignment in introductory biology, but other faculty also will be using various of our panoramic vistas in higher level animal diversity courses. The specific use of the forest panorama depends in large part on the assignment designated by the instructor as well as the context of the specific course topic.

The flexibility of the panorama learning object lies in the ability of an instructor to customize it for a specific use or audience level. To achieve maximal flexibility, we have embedded all video clips on HTML pages rather than compiling them into the panoramic movie itself. This allows instructors to access individual pages and edit them by using the most basic features of any web editor. Thus, instructors can substitute video clips of their choice for those that we have provided. They can add text, animations, links to additional video, or even links to outside web sites to each of the nine "region" pages. As long as a page's file name is not changed, it will remain linked to its designated hotspot in the panorama. If an instructor has access to QuickTime Pro, it is easy to remove the audio tracks from our video clips and record new audio that is more appropriate for a different audience. Combining these customizable features with the ability to create a wide range of assignments means that faculty can utilize the forest panorama, or other of our panoramic vistas at levels ranging from kindergarten (see how many hidden animals you can find) to a sophisticated course at the graduate level. In the latter case, editing could provide a wider range of organisms with a more taxonomic approach, including the scientific names of each species.

\section{Assessment of Effectiveness}

Reports from the 500 educators who assessed the effectiveness of the videographic images of the type used in our hotspots were very positive (Black et al., 2007), and we believe that their integration into a wider ecological context will enhance their appeal. Various authors have emphasized the increased effectiveness of using multiple approaches to learning; (e.g., Mayer, 2002; Black et al. 2007), and Tanenbaum (1998) found that it was often necessary to add contextual cues to a message to convey the varied aspects of the message itself. The components of the features incorporated into the panoramic vistas previously have been shown to enhance learning, e.g., combing auditory and visual modes of communication (Black et al. 2007) and interactivity (NiedzlekFeaver et al., 2004).

\section{Commercial Viability}

Since our goal, as well as that of the funding agency that provided the equipment, and of the university at which the development took place, was to produce an instrument that would improve quality of education in the biological sciences and enable educators to improve their capacity for effective tools that would appeal to their students and enhance their learning experience, our product is not viewed as a commercial venture. It is planned, however, to provide CDs containing topically grouped panoramic vistas to Natural History Museums and other public institutions for sale in their shops at a minimal price. This is not viewed as a profit-making venture, but rather as a means of funding the continuation of video production. We are currently working on panoramas of the North Carolina sand-hills and a swamp environment. Our long-term goal is to offer learning objects of all ecosystems found in North Carolina to the North Carolina Museum of Natural Science for sale and/or educational display. 
North Carolina State University holds the copyright to all of our material. The videos and learning objects that we produce are made available to educators around the world free of charge. Video clips and learning objects, including the forest panorama, may be accessed from the North Carolina Learning Object Repository at http://www.explorethelor.org/. Entering the search term "biomovies" at this site will bring up a list of our products. Educators are encouraged to view, download, and modify our learning objects. All videos and learning objects may be freely used for educational purposes under a Creative Commons license.

\section{Conclusions}

Interactive multimedia panoramic vistas were created as teaching instruments. These involve an image that scans the horizon of a particular habitat and which can be revolved by moving the mouse. Hotspots are embedded in this image that when clicked bring up videos of animals from that habitat and which contain narration pointing out the important attributes of the animal. The forest panorama learning object has been successfully used in an online ecosystems laboratory in a college introductory biology course. This learning object is customizable so that clients can change the audio and insert or delete videos. This panorama, and other products developed by the authors are available gratis to educators via a website of the North Carolina Learning Object Repository.

\section{References}

Black, B. L., Heatwole, H. and Meeks, H. (2007). Using multimedia in interactive learning objects to meet emerging academic challenges. Chapter 6 (pp. 209-257) In A. Koohang and K. Harman (Eds.), Learning Objects: Theory, Praxis, Issues, and Trend. Santa Rosa, California: Informing Science Press,

Brown, B. L. 1997. New learning strategies for generation X. ERIC Digest, 184, 1-7.

Brown, J. S. (2005). Learning in the digital age. Retrieved July 10, 2005, from Educause database, http://www.educause.edu

Brumfield, R. (2005). Study IDs barrier to digital learning. eSchool News, 8 (7), pp. 1, 20.

Dede, C. (1997). Planning for neomillennial learning styles: Implications for investments in technology and faculty. In D. G. Oblinger and J. L. Oblinger (Eds.), Educating the next generation (Chapter 15). EDUCAUSE eBook. Retrieved July 10, 2005, from http://www.educause.edu/content.asp?page_id $=5989 \&$ bhcp $=1$

Mayer, R. E. (2002) Cognitive theory and the design of multimedia instruction: An example of the two-way street between cognition and instruction. New Directions for Teaching and Learning, 89, 55-79.

Niedzlek-Feaver, M., Black, B. L. and Heatwole, H. 2004. The bioMovies project: Developing interactive digital video for active learning environments. Pp. 424-430 in "Proceedings of the $26^{\text {th }}$ Workshop/Conference of the Association for Biology Laboratory Education (ABLE): Vol. 26 "Tested Studies for Laboratory Teaching”, edited by M. A. O’Donnell. Association for Biology Laboratory Education, Bowling Green, Ohio.

Oblinger D. \& Oblinger, L. J. (Eds.) (2005), Educating the next generation (Chapter 15). EDUCAUSE eBook. Retrieved July 10, 2005, from http://www.educause.edu/content.asp?page id=5989\&bhcp=1

Tanenbaum, A. S. (1998). Theoretical Foundations of Multimedia, New York, New York: W. H. Freeman 


\section{Biographies}
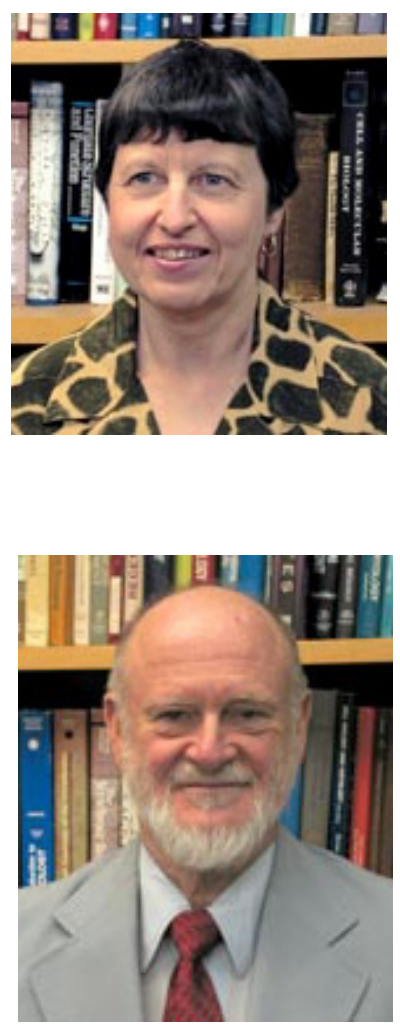

Prof. Harold Heatwole is an ecologist with a BS degree in Botany, an MS in Zoology, a PhD each in Zoology, Botany, and Geography, and a DSc in Herpetology. His research encompasses both invertebrates and vertebrates, has taken him to all seven continents, and has involved vegetation dynamics; community ecology of islands and of deserts; herbivory in tree canopies; thermal ecology and water balance; diving physiology; and population biology; he is one of the foremost authorities in the world on sea snakes. He has published over 300 scientific articles and seven books and edited two multi-volume series: Amphibian Biology; Ecology in Australia. He is president of the Herpetologists' League and was Foundation President of the Australian Coral Reef Society. He is a Fellow of the Explorer's Club. Currently, he is engaged in developing videography as a means of enhancing web-based courses in Zoology. 